\title{
Troglitazone increases the resistance of low density lipoprotein to oxidation in healthy volunteers
}

\author{
L. Cominacini ${ }^{1}$, M. M.R . Young ${ }^{2}$, A . Capriati ${ }^{2}$, U. G arbin ${ }^{1}$, A . Fratta Pasini ${ }^{1}$, M . C ampagnola ${ }^{1}$, A . D avoli ${ }^{1}$, \\ A . R igoni ${ }^{1}$, G. B . Contessi ${ }^{1}$, V. Lo C ascio ${ }^{1}$
}

${ }^{1}$ Istituto di Semeiotica e Nefrologia Medica, University of Verona, Italy

${ }^{2}$ GlaxoWellcome Research and Development Ltd., Greenford, UK

Summary The oxidative modification of low density lipoprotein is of importance in atherogenesis. Antioxidant supplementation has been shown, in published work, to increase low density lipoprotein resistance to oxidation in both healthy subjects and diabetic subjects; in animal studies a contemporary reduction in atherogenesis has been demonstrated. Troglitazone is a novel oral antidiabetic drug which has similarities in structure with vitamin E. The present study assessed the effect of troglitazone $400 \mathrm{mg}$ twice daily for 2 weeks on the resistance of low density lipoprotein to oxidation in healthy male subjects. Ten subjects received troglitazone and ten received placebo in a randomised, placebo-controlled, parallel-group design. The lag phase (a measure of the resistance of low density lipoprotein to oxidation) was determined by measurement of fluorescence development during copper-catalysed oxidative modification of low density lipoprotein. The lag phase was increased by $27 \%$ $(p<0.001)$ at week 1 and by $24 \%(p<0.001)$ at week 2 in the troglitazone treated group compared with the placebo group. A number of variables known to influence the resistance of low density lipoprotein to oxidation were measured. They included macronutrient consumption, plasma and lipoprotein lipid profile, alpha-tocopherol, beta-carotene levels in low density lipoprotein, low density lipoprotein particle size, mono and polyunsaturated fatty acid content of low density lipoprotein and pre-formed low density lipoprotein hydroperoxide levels in low density lipoprotein. Troglitazone was associated with a significant reduction in the amount of pre-formed low density lipoprotein lipid hydroperoxides. At weeks 1 and 2, the low density lipoprotein hydroperoxide content was $17 \%(p<0.05)$ and $18 \%$ $(p<0.05)$ lower in the troglitazone group compared to placebo, respectively. In summary the increase in lag phase duration in the troglitazone group appeared to be due to the compound's activity as an antioxidant and to its ability to reduce the amount of preformed low density lipoprotein lipid hydroperoxides. This antioxidant activity could provide considerable benefit to diabetic patients where atherosclerosis accounts for the majority of total mortality. [Diabetologia (1997) 40: 1211-1218]

Keywords LDL, LDL oxidation, antioxidant, lipid hydroperoxides, atherosclerosis, non-insulin-dependent diabetes mellitus.
Received: 18 February 1997 and in revised form: 6 June 1997

Corresponding author: Dr. L. Cominacini, Istituto di Semeiotica e Nefrologia Medica, Universitá di Verona, Ospedale Policlinico, I-37134 Verona, Italy

A bbreviations: BCA, Bicinchoninic acid; CAD, coronary artery disease; EDTA ethylenediaminetetraacetic acid; HDL, high density lipoprotein; HPLC, high performance liquid chromatography; 15-HETE, 15 hydroxyecosatetraenoic acid; LDL, low density lipoprotein; NIDDM, non-insulin-dependent diabetes (NIDDM); PUFAs, polyunsaturated fatty acids; VLDL, very low density lipoprotein.
Troglitazone, a thiazolidine-2-dione derivative, is a novel oral anti-diabetic drug under development for the treatment of non-insulin-dependent diabetes (NIDDM). It has been reported to enhance insulin sensitivity [1], increase the conversion of glucose to glycogen in rat HepG2 cells [1], reduce hepatic gluconeogenic enzyme activity in rats and mice [2] and to improve metabolic control in NIDDM patients [3,4].

There is a much increased risk of coronary artery disease (CAD) in diabetes and around $60 \%$ of the 
total mortality in diabetes is due to atherosclerosis and subsequent complications [5]. The reasons for this are not fully understood. However it is known that certain post-secretory modifications in the structure of lipoproteins, including the oxidative modifications of low density lipoprotein (LDL), render them more atherogenic [6]. LDL oxidation occurs within the artery wall; it is inhibited in plasma where many defence systems such as antioxidants and metal ion binding proteins exist [6]. Since oxidised LDL cannot be obtained from whole blood, considerable research has involved measurement of the susceptibility to in vitro oxidation of isolated LDL particles [7, 8]. This is increased in patient groups with CAD $[9,10]$ and at risk of developing CAD [11, 12]. Antioxidant supplementation has been shown to reduce the progression of atherosclerotic lesions in Watanabe hyperlipidaemic rabbits [13] and to increase the resistance of LDL to oxidation in both healthy subjects $[14,15]$ and diabetic subjects [16]. Two large-scale studies have shown that supplementation with high doses of vitamin $\mathrm{E}$ was associated with significantly decreased risk of CAD $[17,18]$. Troglitazone has similarities in structure with vitamin $\mathrm{E}$. In vitro studies $[19,20]$, in which the compound was added to pooled plasma, indicated that the compound possessed antioxidant activity, probably acting as a free radical scavenger. The present study compares the effect of troglitazone with that of placebo, administered to healthy volunteers, on the susceptibility of LDL to copper-mediated oxidation. The study also analyses data for variables which are known to influence the susceptibility of LDL to oxidation, and which may aid interpretation of results. These include the LDL fatty acid composition, alpha-tocopherol and beta-carotene concentrations, hydroperoxide concentration and LDL particle size.

\section{Materials and methods}

Subjects. Twenty healthy male subjects aged between 21 and 45 years, with a body mass index ranging between 20 and 29 $\mathrm{kg} / \mathrm{m}^{2}$, a fasting plasma glucose of $<5.5 \mathrm{mmol} / \mathrm{l}$ and fasting plasma total cholesterol and triglyceride levels of $<5.81$ and $<1.80 \mathrm{mmol} / \mathrm{l}$ respectively, participated in the study. The subjects were free from significant cardiac, hepatic, renal, pulmonary, neurological, gastrointestinal, haematological, metabolic and psychiatric disease as determined by history, physical examination and laboratory screen. Subjects who had received a regular course of medication during the 4 weeks prior to the study, cholesterol lowering medications or vitamin supplementation during the previous 3 months, or probucol during the previous 12 months were excluded from the study. Subjects who smoked more than 5 cigarettes a day or who regularly drank more than 4 units of alcohol per day or who drank excessive coffee were excluded from the study. Subjects received a full verbal and written explanation of the nature and purposes of the study and each gave written informed consent prior to participation in the study. The study was conducted in accordance with the Declaration of Helsinki, and its revisions.
Safety evaluations. Subjects underwent a medical examination which included history, physical examination, 12-lead ECG and laboratory safety screens during the 3 weeks prior to the first dose.

Further blood and urine samples for laboratory safety tests were obtained pre-dose 1 (day 1), pre-dose 29 (day 15) and 2 weeks after the last dose (day 29).

Treatment details. This was a double-blind, randomised, placebo-controlled, parallel group study, in which 10 subjects received troglitazone $400 \mathrm{mg}$ (as $2 \times 200 \mathrm{mg}$ tablets) and $10 \mathrm{re}-$ ceived matching placebo, twice daily for 14.5 days.

Subjects were randomly assigned to one of two groups to receive treatment according to the randomisation code. Doses were taken with $100 \mathrm{ml}$ water, at the start of breakfast and evening dinner at approximately $12 \mathrm{~h}$ intervals.

During the study period, from 1 week prior to the first dose until 2 weeks after the last dose, the subjects were required to: 1) adhere strictly to their usual diet and lifestyle, avoiding excess; 2) not consume more than 4 cups of caffeinated coffee per day; 3 ) avoid strenuous exercise which was not part of their usual routine; 4 ) not smoke for $24 \mathrm{~h}$ before any blood sample in the study period; 5) not consume more than 4 units of alcohol per day; 6) not take any other medication.

Food intake. The quantity and type of food consumed throughout the 5 week study period was recorded in a food diary. Total calories consumed per week, lipid, protein and carbohydrate consumption ( $\%$, total calories/week), were determined as previously described [21]; subjects used a conversion table to convert "portions" of various foods into weight in grams.

M ethods. Subjects fasted from 21.30 hours on the evenings prior to blood sampling. Blood samples $(5 \mathrm{ml}$ into lithium heparin for plasma troglitazone assay and $60 \mathrm{ml}$ into EDTA $1 \mathrm{mg} / \mathrm{ml}$ ) were obtained by venepuncture between $08.00-08.45$ hours (i.e. $12 \mathrm{~h} \pm 45 \mathrm{~min}$ after the previous dose) on the following occasions: pre-dose 1 (day 1), pre-dose 15 (day 8), pre-dose 29 (day 15), 2 weeks post study (day 29). Additional samples were obtained at $2 \mathrm{~h}$ post doses 1 and 29. The tubes were kept on ice and centrifuged at $2000 \mathrm{rev} / \mathrm{min}$ for $20 \mathrm{~min}$ at $4{ }^{\circ} \mathrm{C}$ within approximately $15 \mathrm{~min}$ of collection. The plasma was processed for the separation of lipoprotein within $5 \mathrm{~h}$.

The following variables were measured at each time point: plasma, high density lipoprotein (HDL), LDL and very low density lipoprotein (VLDL) cholesterol and triglyceride; susceptibility of LDL to in vitro copper-mediated oxidative modification; alpha-tocopherol and beta-carotene content of LDL; LDL hydroperoxides as 15 hydroxyecosatetraenoic acid (15HETE); LDL mono (oleic acid) and polyunsaturated (linoleic, linolenic, arachidonic, eicosapentaenoic acids) fatty acids; LDL particle size; plasma and LDL troglitazone concentrations.

L ipoprotein separation. Lipoproteins were isolated by sequential ultracentrifugation in $\mathrm{NaBr}$ solutions [22] containing $1 \mathrm{mg} / \mathrm{ml}$ EDTA and stored at $4{ }^{\circ} \mathrm{C}$. LDL was stored under nitrogen at $4^{\circ} \mathrm{C}$ in a sterile, dark environment and used within 1 day. Cholesterol and triglyceride levels in plasma and lipoprotein fractions were determined by Technicon autoanalyzer II (Technicon, Instruments Corp., Tarrytown, N.Y., USA) methodology. Protein was measured by the Pierce BCA protein assay reagent [23].

LDL oxidation. The method for LDL oxidation with $\mathrm{Cu}^{++}$ and for the evaluation of its susceptibility to oxidation, i.e. evaluation of the length of the lag phase, was based on 
Table 1. Lag phase ( $\mathrm{min}$ ) during multiple oral administration of troglitazone $400 \mathrm{mg}$ twice daily or placebo: statistical analysis

\begin{tabular}{|c|c|c|c|c|c|}
\hline Occasion & $\begin{array}{l}\text { Troglitazone } \\
\text { adjusted mean } \\
(\mathrm{n}=10)\end{array}$ & $\begin{array}{l}\text { Placebo } \\
\text { adjusted mean } \\
(n=9)\end{array}$ & Ratio (T/P) & $\begin{array}{l}95 \% \\
\text { confidence interval }\end{array}$ & $p$-value \\
\hline $2 \mathrm{~h}$ post-dose 1 (day 1$)$ & 81.6 & 74.3 & 1.10 & $(1.01,1.19)$ & 0.030 \\
\hline Pre-dose 29 (day 15) & 97.9 & 79.2 & 1.24 & $(1.13,1.35)$ & $<0.001$ \\
\hline 2 h post-dose 29 (day 15$)$ & 93.7 & 74.9 & 1.25 & $(1.15,1.36)$ & $<0.001$ \\
\hline 2 weeks post study (day 29) & 80.5 & 74.8 & 1.08 & $(1.00,1.16)$ & 0.056 \\
\hline
\end{tabular}

${ }^{a}$ Geometric mean adjusted for pre-dose values

development of fluorescence during copper-catalysed LDL oxidative modification as described [8].

A Ipha-tocopherol and beta-carotene measurement. LDL alphatocopherol was measured by an HPLC method as previously described [24]. Beta-carotene was evaluated from the absorbance of LDL lipid extract at $450 \mathrm{~nm}$ using an extinction coefficient of $2590 \mathrm{mmol} / 1 \cdot \mathrm{cm}^{-1}$.

LDL hydroperoxide assay. For LDL hydroperoxide assay, aliquots of $\mathrm{LDL}$ were frozen at $-80^{\circ} \mathrm{C}$ immediately after LDL was separated by ultracentrifugation. LDL hydroperoxides were measured as 15 -HETE by a radioimmunoassay method using a commercially available kit (PerSeptive Diagnostics, Cambridge, Mass., USA). Prior to measurement 15-HETE was extracted as previously reported [25]. The sensitivity of the method was about $2.5 \mathrm{pg} / 0.1 \mathrm{ml}$. The intra-assay variation was less than $4 \%$.

LDL fatty acid content. LDL fatty acid content was analysed by gas-liquid chromatography [26]. Analysis was performed on a Hewlett-Packard 5890 II with a flame ionisation detector.

L D L particle composition and size. LDL size was estimated indirectly from the ratio of core (cholesteryl ester and triglyceride) to surface (protein, free cholesterol and phospholipid) components $[27,28]$. Free cholesterol and phospholipids were measured by commercially available enzymatic reagents (Boehringer-Mannheim, Mannheim, Germany). Cholesteryl ester was derived from total-free cholesterol.

Troglitazone concentration. Troglitazone was extracted from plasma samples with a mixture of ethyl acetate and hexane and the extract analysed by liquid chromatography with ultra violet detection. Troglitazone was analysed in LDL in a similar manner except that solvent precipitation was used rather than solvent extraction. The lower limit of quantification for the assay was $100 \mathrm{ng} / \mathrm{ml}$ in plasma and $10 \mathrm{ng} / \mathrm{ml}$ in LDL.

Statistical analysis. Parameters were analysed separately using analysis of covariance allowing for effects due to treatment and including the relevant pre-dose 1 value as covariate. All parameters, except for calorie intake per week and the proportion consumed as lipid, carbohydrate or protein and body weight, were log transformed prior to analysis in order to improve the assumptions of homogeneity of variance and normality of distribution. For each parameter that was log transformed an estimate of the ratio of the adjusted geometric means for troglitazone relative to placebo was obtained together with a $95 \%$ confidence interval and was tested for significance.

\section{Results}

Twenty subjects completed this study with no withdrawals. All adverse events reported were of a minor nature and none could be attributed with certainty to the administration of study treatments.

In one subject in the placebo group the plasma triglyceride level, although within the normal range at screening, was elevated at day $1(376 \mathrm{mg} / \mathrm{dl}$, pre-dose 1) decreasing thereafter. All data for this subject have been omitted from the calculation of means and from the statistical analysis.

Body weight and food intake. Body weight did not change during the study. Neither the total calorie consumption nor the percentage of calories consumed as lipid, or carbohydrate, changed significantly during the study. A statistically significant difference between the treatment groups was observed for the percentage of calories consumed as protein during week 2 such that consumption was $12 \%$ lower $(p=0.017)$ in the troglitazone group.

Plasma and L D L troglitazone concentrations. Median plasma trough concentrations of troglitazone predose 15 and pre-dose 29 were $496 \mathrm{ng} / \mathrm{ml}$ (range 254850 ) and $420 \mathrm{ng} / \mathrm{ml}$ (range 208-565) respectively; at $2 \mathrm{~h}$ post-doses 1 and 29 they were $1715 \mathrm{ng} / \mathrm{ml}$ (range 1010-2490) and $1985 \mathrm{ng} / \mathrm{ml}$ (range 1120-2540). The amount of troglitazone incorporated into LDL was small, with median values of $32 \mathrm{ng} / \mathrm{mg}$ LDL protein (range 19-85) and $32 \mathrm{ng} / \mathrm{mg}$ LDL protein (range 1048) pre-dose 15 and pre-dose 29 respectively. Values of troglitazone in the $2 \mathrm{~h}$ post-dose 1 and 29 samples were higher than those found pre-dose. Median values were $125 \mathrm{ng} / \mathrm{mg}$ LDL protein (range 65-174) and $159 \mathrm{ng} / \mathrm{mg}$ LDL protein (range 79-213) respectively.

$L$ ag phase. The geometric mean lag phase for the placebo group pre-dose 1 was 83.1 min (range 70.5$106.2 \mathrm{~min}$ ) and for the troglitazone group was 76.4 min (range 66.9-93.4 min). Adjusted mean values and the statistical analysis of lag phase are shown in Table 1. The duration of the lag phase (i.e. the resistance to LDL to oxidation) increased significantly during troglitazone administration. The lag phase 


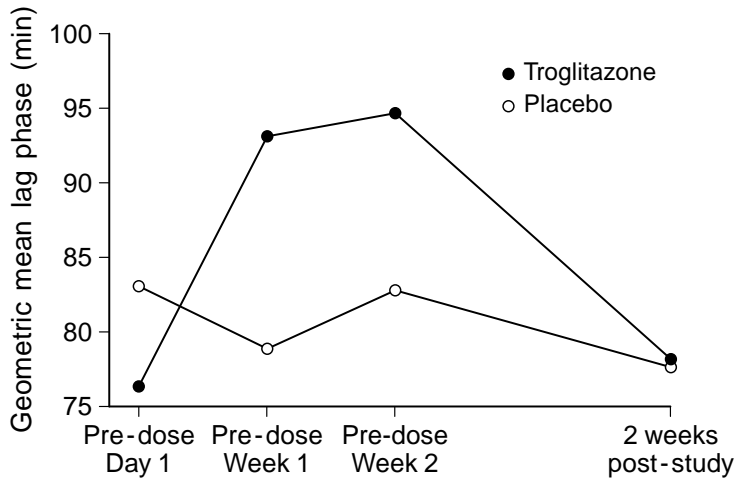

Fig. 1. Geometric mean lag phase for the oxidative modification of LDL from healthy subjects against time

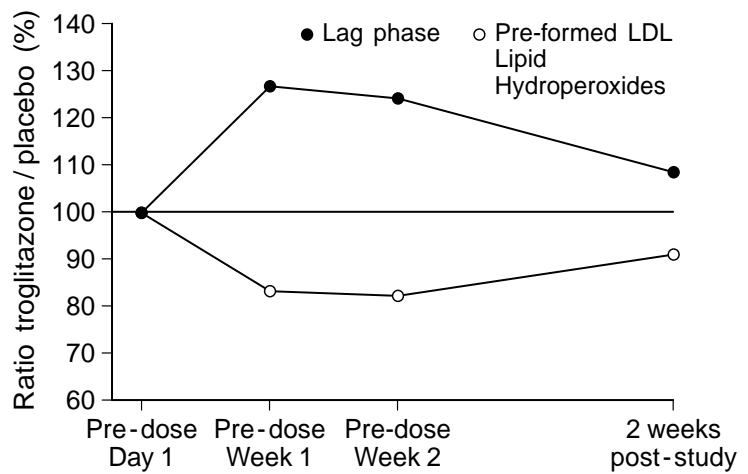

Fig. 2. Ratio (\%) of adjusted means for troglitazone $400 \mathrm{mg}$ twice daily and placebo at each time point for lag phase (upper section) and pre-formed LDL lipid hydroperoxides (lower section)

was $27 \%(\mathrm{CI} 22 \%, 32 \% ; \mathrm{p}<0.001)$ and $24 \%(\mathrm{CI}$ $13 \%, 35 \% ; p<0.001)$ higher in the troglitazone group compared to the placebo group at pre-dose 15 (week 1) and pre-dose 29 (week 2), respectively. The geometric mean lag phase for the oxidative modification of LDL from healthy subjects against time is represented in Figure 1. Troglitazone also increased the duration of the lag phase in the $2 \mathrm{~h}$ post-dose samples (Table 1). The lag phase was 10 and $25 \%$ higher in the troglitazone group compared to the placebo group post-doses 1 and 29, respectively. Both increases were statistically significant.

LDL preformed lipid hydroperoxides. Adjusted mean values and the statistical analysis of LDL hydroperoxides are shown in Table 2. Troglitazone significantly reduced the amount of LDL lipid hydroperoxides. At weeks 1 and 2 the pre-dose LDL lipid hydroperoxides content was $17 \%$ (CI 5\%, $28 \%$; $\mathrm{p}<0.05)$ and $18 \%(\mathrm{CI} 2 \%, 32 \% ; p<0.05)$ lower in the troglitazone group compared to placebo, respectively. Figure 2 shows the ratio (\%) of adjusted means for troglitazone $400 \mathrm{mg}$ twice daily and placebo at each time point for lag phase (upper section) and pre-formed LDL lipid hydroperoxides (lower section). Interestingly the highest values of lag phase matched the lowest concentrations of pre-formed LDL hydroperoxides.

O ther parameters. There were no changes in plasma and lipoprotein cholesterol. Plasma and VLDL triglyceride levels in the fasting samples obtained predose 15, pre-dose 29 and 2 weeks post study did not change significantly during the study. Non-fasting plasma and VLDL triglyceride concentrations at $2 \mathrm{~h}$ post-dose 1 were 23 and $22 \%$ lower in the troglitazone group compared to the placebo $(p=0.002$ and $p=0.014$, respectively). These effects were not seen at $2 \mathrm{~h}$ post-dose 29. Adjusted mean values and the statistical analysis of plasma triglycerides are shown in Table 3. LDL and HDL triglyceride levels did not change during the study. No statistically significant differences were observed between the two treatment groups for levels of alpha-tocopherol and betacarotene. There were no changes in LDL particle size. Adjusted mean values and the statistical analysis of LDL size are shown in Table 4. There were no changes in polyunsaturated fatty acids (PUFAs) measured: linoleic, linolenic, arachidonic and eicosapentaenoic acid. A statistically significant difference between the treatment groups was observed pre-dose 15 with oleic acid $21 \%$ higher in the troglitazone group compared to the placebo group $(p=0.049)$. However the ratio of LDL oleic acid content to linoleic acid content did not significantly change during the study. Adjusted mean values and the statistical analysis for oleic acid and for the major LDL PUFAs (linoleic and arachidonic acid) are shown in Table 5.

\section{Discussion}

In view of the difficulties in identifying oxidised lipoprotein in plasma, many workers have attempted to analyse the oxidation susceptibility of isolated LDL particles $[7,8]$. There is growing evidence of a relationship between susceptibility of LDL to oxidation and atherosclerotic risk [9-12]. Furthermore the reduced progression of atherosclerosis in antioxidanttreated animals is associated with decreased susceptibility of LDL to oxidation [29]. A novel strategy in the prevention of atherosclerosis could therefore be to prevent the deleterious effect of oxidised LDL by reducing the oxidation rate of LDL. In the present study the administration of troglitazone $400 \mathrm{mg}$ twice daily for 2 weeks to healthy subjects increased the lag phase by approximately $24 \%$. This effect was evident at both 1 and 2 weeks of treatment. Our data are consistent with other studies in which an increase of LDL antioxidants, by incubation or oral supplementation, always resulted in a strict proportional increase in the length of the lag phase $[14,20,15,30]$. Oxidative 
Table 2. LDL lipid hydroperoxides (pg/mg LDL protein) during multiple oral administration of troglitazone $400 \mathrm{mg}$ twice daily or placebo: statistical analysis

\begin{tabular}{|c|c|c|c|c|c|}
\hline Occasion & $\begin{array}{l}\text { Troglitazone } \\
\text { adjusted mean } \\
(\mathrm{n}=10)\end{array}$ & $\begin{array}{l}\text { Placebo } \\
\text { adjusted mean } \\
(n=9)\end{array}$ & Ratio (T/P) & $\begin{array}{l}95 \% \\
\text { confidence interval }\end{array}$ & $p$-value \\
\hline $2 \mathrm{~h}$ post-dose 1 (day 1$)$ & 1010 & 1168 & 0.86 & $(0.78,0.96)$ & $<0.009$ \\
\hline Pre-dose 29 (day 15) & 865 & 1059 & 0.82 & $(0.68,0.98)$ & $<0.036$ \\
\hline $2 \mathrm{~h}$ post-dose 29 (day 15$)$ & 916 & 1141 & 0.80 & $(0.69,0.94)$ & $<0.001$ \\
\hline 2 weeks post study (day 29 ) & 948 & 1046 & 0.91 & $(0.78,1.06)$ & $<0.197$ \\
\hline
\end{tabular}

${ }^{a}$ Geometric mean adjusted for pre-dose values

Table 3. Plasma triglycerides (mmol/l) during multiple oral administration of troglitazone $400 \mathrm{mg}$ twice daily or placebo

\begin{tabular}{|c|c|c|c|c|c|}
\hline Occasion & $\begin{array}{l}\text { Troglitazone } \\
\text { adjusted mean } \\
(\mathrm{n}=10)\end{array}$ & $\begin{array}{l}\text { Placebo } \\
\text { adjusted mean } \\
(n=9)\end{array}$ & Ratio (T/P) & $\begin{array}{l}95 \% \\
\text { confidence interval }\end{array}$ & $p$-value \\
\hline 2 h post-dose 1 (day 1$)$ & 0.89 & 1.16 & 0.77 & $(0.66,0.89)$ & $<0.002$ \\
\hline Pre-dose 29 (day 15) & 0.98 & 0.94 & 1.04 & $(0.80,1.39)$ & $<0.709$ \\
\hline $2 \mathrm{~h}$ post-dose 29 (day 15$)$ & 0.92 & 1.09 & 0.84 & $(0.66,1.10)$ & $<0.204$ \\
\hline 2 weeks post study (day 29 ) & 0.85 & 0.99 & 0.86 & $(0.59,1.23)$ & $<0.363$ \\
\hline
\end{tabular}

${ }^{a}$ Geometric mean adjusted for pre-dose values

Table 4. LDL size (ratio of core to surface LDL components) during multiple oral administration of troglitazone $400 \mathrm{mg}$ twice daily or placebo

\begin{tabular}{|c|c|c|c|c|c|}
\hline Occasion & $\begin{array}{l}\text { Troglitazone } \\
\text { adjusted mean } \\
(\mathrm{n}=10)\end{array}$ & $\begin{array}{l}\text { Placebo } \\
\text { adjusted mean } \\
(n=9)\end{array}$ & Ratio (T/P) & $\begin{array}{l}95 \% \\
\text { confidence interval }\end{array}$ & $p$-value \\
\hline $2 \mathrm{~h}$ post-dose 1 (day- 1$)$ & 0.694 & 0.676 & 1.03 & $(0.99,1.06)$ & $<0.120$ \\
\hline Pre-dose 29 (day 15) & 0.703 & 0.730 & 0.96 & $(0.91,1.02)$ & $<0.182$ \\
\hline $2 \mathrm{~h}$ post-dose 29 (day 15$)$ & 0.698 & 0.701 & 1.00 & $(0.97,1.03)$ & $<0.801$ \\
\hline 2 weeks post study (day 29) & 0.697 & 0.693 & 1.01 & $(0.98,1.03)$ & $<0.659$ \\
\hline
\end{tabular}

${ }^{\text {a }}$ Geometric mean adjusted for pre-dose values

modification begins only when LDL has been largely depleted of its antioxidants [31], which suggests that the lag phase is mainly determined by the antioxidant content. On a molar basis, the major antioxidant in LDL is vitamin E, a chain breaking antioxidant. Nevertheless, vitamin E levels in LDL do not correlate with the duration of lag phase in non-supplemented subjects [14]. Vitamin $E$ is therefore important, but not the only variable which determines the resistance of LDL to oxidation.

Prospective epidemiological studies have shown that phenotype B with small dense LDL is associated with an increased risk of CAD [32]. De Graaf et al. [33] separated LDL of normal subjects in three subfractions (LDL1: very light, LDL2: light, LDL3: dense) and assessed their oxidation resistance by measuring the diene compared to time profile in copper stimulated oxidation. They reported that dense LDL fractions (LDL2, LDL3) had a reduced lag phase $(-20 \%)$ and contained more conjugated diene after $4 \mathrm{~h}$ oxidation, probably due to their higher content in PUFAs. These results were also confirmed in patients with familial hypertriglyceridaemia, insulin-dependent and non-insulin-dependent diabetes and with coronary heart disease [28]. Furthermore it is generally believed that the amount of PUFAs and oleic acid in the LDL could be important for its susceptibility to oxidation $[11,34]$. The first step in the LDL lipid peroxidation, in fact, is the formation of monohydroperoxy derivatives of fatty acids and linoleic and arachidonic acids have been demonstrated to be more susceptible to forming monohydroperoxy derivatives than other fatty acids [35]. Actually Esterbauer et al. [31] proposed a scheme in which the role of the copper in the oxidative process of LDL is to catalyse the conversion of trace amounts of preformed lipid hydroperoxides to alkoxy and peroxy radicals, which in turn start another round of lipid peroxidation. More recently Yoshida and Niki [36] reported that the rate of copper-catalysed oxidation of methyl linoleate, was proportional to the half power of the initial preformed peroxide concentration. 
Table 5. LDL oleic, linoleic and arachidonic acid ( $\mu \mathrm{g} / \mathrm{mg}$ LDL protein) during multiple oral administration of troglitazone $400 \mathrm{mg}$ twice daily or placebo

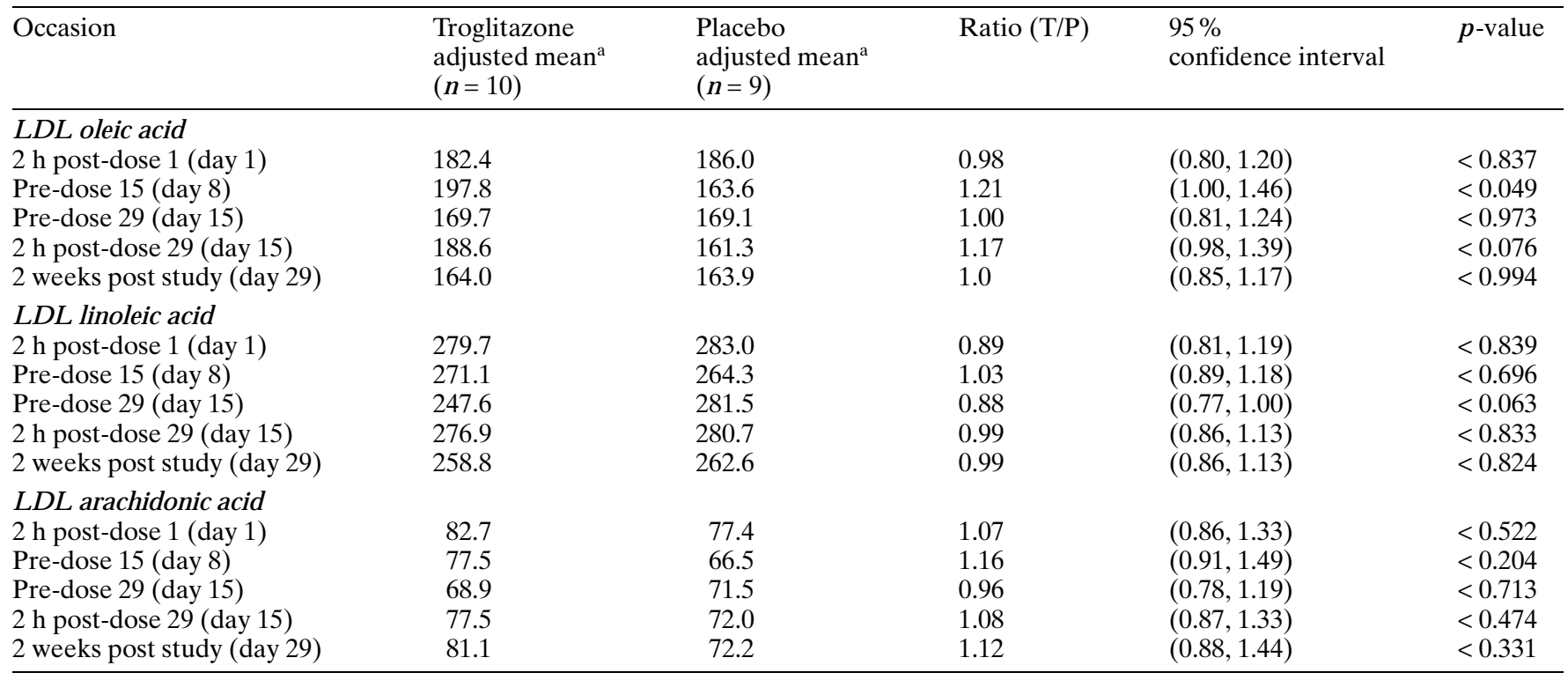

${ }^{a}$ Geometric mean adjusted for pre-dose values

Moreover it has been demonstrated that Ebselen, a synthetic Se-containing compound possessing peroxidase activity, totally prevented the oxidative modification of LDL by $\mathrm{Cu}^{++}[37]$.

A number of variables known to influence the resistance of LDL to oxidation were therefore measured in this study. There were no consistently significant differences between the treatment groups in total calories consumed as lipid protein or carbohydrate. Alpha-tocopherol and beta-carotene levels in LDL did not alter significantly during the study period. As for the lipid profile, there were no changes in plasma and lipoprotein cholesterol. Fasting triglyceride values did not change during the study. Non-fasting plasma triglyceride at $2 \mathrm{~h}$ post-dose 1 (but not at $2 \mathrm{~h}$ post-dose 29 ) were $23 \%$ lower in the troglitazone group compared to the placebo. This is an interesting finding that implies that troglitazone may have as yet unexplored therapeutic effects on altered postprandial triglyceridemic response, a condition associated with increased progression of coronary artery lesions [38]. The likelihood that postprandial triglycerides may be affected by a drug which has blood glucose lowering effect and in particular an effect on fatty acid metabolism through its effect on insulin action should be considered. Unfortunately in this study we did not measure pre and postprandial blood glucose or insulin. The present data therefore allow no definitive conclusion on the matter and this point requires further study. Considering triglyceride is thought to be very important in influencing LDL size [39], a change in particle size was expected at $2 \mathrm{~h}$ post-dose 1. LDL particle size, however, did not change during the study possibly because of the small triglyceride changes. We can reasonably conclude therefore that the change in lag phase at $2 \mathrm{~h}$ post-dose 1 is unlikely to be due to alteration of LDL particle size.

There were fluctuations in the amounts of oleic acid and PUFAs, but these fluctuations were small and unlikely to have influenced the resistance of LDL to oxidation. Consistently there were no changes in the ratio of LDL oleic acid content to linoleic acid content which is considered one of the most important determinants of the susceptibility of LDL to oxidation [34].

At variance with these variables, the administration of troglitazone $400 \mathrm{mg}$ twice daily for 2 weeks significantly reduced the preformed LDL lipid hydroperoxides at pre-dose 15 and 29 without any significant change in oleic or PUFA composition. Recent studies demonstrated that native LDL contains preformed lipid hydroperoxides [40-42] and that they were stable in plasma [43]. The increase in lag phase induced by troglitazone administration may, therefore, be due not only to its radical scavenging activity but also to its ability to reduce trace amounts of preformed lipid hydroperoxides in LDL. The results are consistent with the classic kinetic model proposed by Niki for lipid peroxidation [44], where the length of the lag phase is directly related to the amount of antioxidants and inversely related to the initiation rate and therefore to the amount of preformed lipid hydroperoxides and to the products formed from their decomposition by $\mathrm{Cu}^{++}$. Open questions are why LDL contains hydroperoxides and how troglitazone can reduce their concentrations.

The results of this study also show that the increase in lag phase observed pre-dose was similar to that 
observed at peak troglitazone concentrations $(2 \mathrm{~h}$ post-dose), suggesting that the increase in resistance of LDL to oxidation was maintained for the duration of the dosing interval. It has to be emphasized, however, that the pre and post-troglitazone LDL levels were different, the latter being higher than the former. Even if on the basis of the present results we cannot draw any definitive conclusion on this point, a contamination of LDL fraction from the elevated troglitazone plasma concentration at $2 \mathrm{~h}$ post-dose 1 , could be a likely explanation. This hypothesis is supported by our previous in vitro study showing a direct highly significant relationship between the length of lag phase and the troglitazone LDL concentration [20].

In conclusion the administration of troglitazone $400 \mathrm{mg}$ twice daily for 2 weeks increased the resistance of LDL to copper-mediated oxidation by approximately $24 \%$. The increase in lag phase duration in the troglitazone group appeared to be due to the compound's activity as an antioxidant and to its ability to reduce the amount of pre-formed LDL lipid hydroperoxides.

\section{References}

1. Ciaraldi TP, Gilmore A, Olefsky JM (1990) In vitro studies on the action of CS-045, a new antidiabetic agent. Metabolism 39: 1056-1062

2. Fujiwara T, Yoshioca S, Yoshioca T (1988) Characterization of new oral antidiabetic agent CS-045. Diabetes 37: $1549-1555$

3. Iwamoto Y, Kosaka K, Kuzuya T, Akanuma Y, Shigeta Y, Kaneko T (1996) Effects of troglitazone: a new hypoglycemic agent in patients with NIDDM poorly controlled by diet therapy. Diabetes Care 19: 151-156

4. Kumar S, Boulton AJM, Beck-Nielsen H et al. (1996) Troglitazone, an insulin action enhancer, improves metabolic control in NIDDM patients. Diabetologia 39: 701-709

5. Steiner C (1985) Atherosclerosis, the major complication of diabetes. Adv Exp Med Biol 189: 277-297

6. Steinberg D, Parthasarathy S, Carew TE, Khoo JC, Witztum JL (1989) Modifications of low-density lipoprotein that increase its atherogenicity. N Engl J Med 14: 915-924

7. Esterbauer H, Jurgens G, Quehenberger O, Koller E (1987) Autoxidation of human low density lipoprotein: loss of polyunsaturated fatty acids and vitamin $\mathrm{E}$ and generation of aldehydes. J Lipid Res 28: 495-509

8. Cominacini L, Garbin U, Davoli A et al. (1991) A simple test for predisposition to LDL oxidation based on the fluorescence development during copper-catalyzed oxidative modification. J Lipid Res 32: 349-358

9. Regnstrom JN, Nilsson J, Tornavall P, Landou C, Hamsten A (1992) Susceptibility to low-density lipoprotein oxidation and coronary atherosclerosis in man. Lancet 339: $1183-1186$

10. Cominacini L, Garbin U, Pastorino M et al. (1993) Predisposition to LDL oxidation in patients with and without angiographically established coronary artery disease. Atherosclerosis 99: 63-70

11. Cominacini L, Pastorino AM, Garbin U et al. (1994) The susceptibility of LDL to in vitro oxidation is increased in hypercholesterolemic patients. Nutrition 10: 527-531
12. Cominacini L, Garbin U, Pastorino AM et al. (1994) Increased susceptibility of LDL to in vitro oxidation in patients with insulin-dependent and non-insulin-dependent diabetes mellitus. Diab Res 26: 173-184

13. Mao SJ, Yates MT, Rechtin AE, Jackson RI, Van Sickle WA (1991) Antioxidant activity of probucol and its analogues in hypercholesterolemic Watanabe rabbits. J Med Chem 34: 298-302

14. Cominacini L, Garbin U, Cenci B et al. (1991) Predisposition to LDL oxidation during copper-catalyzed oxidative modification and its relation to alpha-tocopherol content in humans. Clin Chim Acta 204: 57-68

15. Dieber-Rotheneder M, Puhl H, Waeg G, Striegl G, Esterbauer H (1991) Effect of oral supplementation with alphatocopherol on the vitamin E content of human low density lipoproteins and resistance to oxidation. J Lipid Res 32: $1325-1332$

16. Babiy AV, Gebicky JM, Sullivan DR (1992) Increased oxidazibility of plasma lipoproteins in diabetic patients can be decreased by probucol therapy and is not due to glycation. Biochem Pharmacol 43: 995-1000

17. Rimm EB, Stampfer MJ, Ascherio A, Giovannucci E, Colditz GA Willet WC (1993) Vitamin E consumption and the risk of coronary heart disease in men. N Engl J Med 328: $1450-1456$

18 Stampfer MJ, Hennekens CH, Manson JE, Colditz GA, Rosner B, Willet WC (1993) Vitamin E consumption and the risk of coronary heart disease in women. $\mathrm{N}$ Engl $\mathrm{J}$ Med 328:1444-1449

19. Noguchi N, Sakai H, Kato Y et al. (1996) Inhibition of oxidation of low density lipoprotein by troglitazone. Atherosclerosis 123: 227-234

20. Cominacini L, Garbin U, Pastorino AM et al. (1997) Effects of troglitazone on in vitro oxidation of LDL and HDL induced by copper ions and endothelial cells. Diabetologia 40: 165-172

21. Cominacini L, Zocca I, Garbin U et al. (1988) Long-term effect of a low-fat, high-carbohydrate diet on plasma lipids of patients affected by familial endogenous hypertriglyceridemia. Am J Clin Nutr 48: 57-65

22. Havel RJ, Eder MA, Bragdon JM (1955) The distribution and chemical composition of ultracentrifugally separated lipoproteins in human serum. J Clin Invest 34: 13451353

23. Smith PK, Krohn RI, Hermanson GT et al. (1985) Measurement of protein using bicinchoninic acid. Anal Biochem 105: 293-299

24. Lehmann J, Martin HL (1982) Improved direct determination of alpha- and gamma-tocopherol in plasma and platelets by liquid chromatography with fluorescence detection. Clin Chem 28: 1345-1353

25. Cominacini L, Garbin U, Fratta Pasini A et al. (1997) Antioxidants inhibit the expression of intercellular cell adhesion molecule- 1 and vascular cell adhesion molecule- 1 induced by oxidized LDL on human umbilical vein endothelial cells. Free Rad Biol Med 22: 117-127

26. Lepage G, Roy CC (1986) Direct transesterification of all classes of lipids in one-step reaction. J Lipid Res 26: 114118

27. Sata T, Havel RJ, Jones AL (1972) Characterization of subfractions of triglyceride-rich lipoproteins separated by gel chromatography from blood plasma of normolipemic and hyperlipemic humans. J Lipid Res 18: 465-471

28. Cominacini L, Garbin U, Fratta Pasini A et al. (1995) Susceptibility to in vitro oxidation of LDL derived from patients at risk for atherosclerosis: relation to LDL subfraction profile. In: Bellomo GFG, Finardi G, Maggi E, 
Rice-Evans C (eds) Free radicals, lipoprotein oxidation and atherosclerosis. Richelieu Press, London, pp 473-492

29. Sasahara M, Raines EW, Chait A et al. (1994) Inhibition of hypercholesterolemia-induced atherosclerosis in the nonhuman primate by probucol. Is the extent of atherosclerosis related to resistance of LDL to oxidation? J Clin Invest 94: $155-164$

30. Princen HMG, Van Poppel G, Vogelezang C, Buytenhek R, Kok FJ (1992) Supplementation with vitamin E but not beta-carotene in vivo protects low density lipoproteins from lipid peroxidation in vitro. Arterioscler Thromb 12: 554-562

31. Esterbauer H, Rotheneder M, Striegl G et al. (1989) Vitamin $\mathrm{E}$ and other lipophilic antioxidants protect LDL against oxidation. Fat Sci Technol 91: 316-324

32. Austin MA, Breslow JL, Hennekens CH, Buring JE, Wilet WC, Krauss RM (1988) Low density lipoprotein subclass pattern and risk of myocardial infarction. JAMA 260: 1917-1921

33. de Graaf J, Hak-Lemmers HLM, Hectors MPC, Denmarker PNM, Hendriks JCM, Stalenhoef AFH (1991) Enhanced susceptibility to in vitro oxidation of the dense low density lipoprotein subfraction in healthy subjects. Arterioscl Thromb 11: 298-308

34. Kleinveld HA, Naber AHJ, Stalenhoef AFH, Denmarker PNM (1993) Oxidation resistance, oxidation rate, and extent of oxidation of human low-density lipoprotein depend on the ratio of oleic acid content to linoleic acid content: studies in vitamin E deficient subjects. Free Rad Biol Med 15: 273-280

35. Wang T, Yu W, Powell WS (1992) Formation of monohydroxy derivatives of arachidonic acid, linoleic acid, and oleic acid during oxidation of low density lipoprotein by copper ions and endothelial cells. J Lipid Res 33: 525-535
36. Yoshida Y, Niki E (1992) Oxidation of methyl linoleate in acqueous dispersions induced by copper and iron. Arc Biochem Biophys 295: 107-114

37. Thomas CE, Jackson RL (1991) Lipid hydroperoxide involvement in copper-dependent and independent oxidation of low density lipoproteins. J Pharm Expt Ther 256: 1182-1189

38. Patsch JR, Miesenbock G, Hopferwieser Tet al. (1992) Relation of triglyceride metabolism and coronary artery disease: studies in the postprandial state. Arteriosclerosis Thromb 12: 1336-1345

39. McNamara JR Jenner JL, Li Z, Wislon PWF, Schaefer EJ (1992) Change in LDL particle size is associated with change in plasma triglyceride concentration. Arteriosclerosis Thromb 12: 1284-1290.

40. Miyazawa T, Fujimoto K (1990) Determination of lipid hydroperoxides in low density lipoproteins from human plasma using high performance liquid chromatography with chemiluminescent detection. Biomed Chromat 4: 131-134

41. Cominacini L, Pastorino AM, McCarthy A et al. (1993) Determination of lipid hydroperoxides in native low density lipoprotein by a chemiluminescent flow-injection assay. Biochim Biophys Acta 1165: 279-287

42. Zamburlini A, Maiorino M, Barbera P et al. (1995) Measurement of lipid hydroperoxides in plasma lipoproteins by a new highly-sensitive "single photon counting" luminometer. Biochim Biophys Acta 1256: 233-240

43. Pastorino AM, Cominacini L, Maiorino M et al. (1994) Effect of plasma on the degradation of hydroperoxides of unesterified linoleic acid and copper-peroxidized LDL. Free Rad Biol Med 16: 459-463

44. Niki E (1987) Antioxidants in relation to lipid peroxidation. Chem Phys Lipids 44: 227-253 